\title{
Meteorological associations of cerebrovascular disease mortality in England and Wales
}

\author{
E. G. KNOX \\ From the Health Services Research Centre, Birmingham
}

SUMMARY The recent decline in stroke mortality, and its seasonal variation, have not been satisfactorily explained through any single factor. Nevertheless, several causes might operate through a single mechanism, namely salt loss variation. The increased use of diuretics could explain the trend, and physiological salt loss variations might explain the cycle. The associations between mortality and meteorological variables were therefore examined. The examination was negative in that temperature correlations were equally strong in winter and in summer, with no support for the hypothesis that temperature-dependent salt loss was a contributing cause.

It was found in addition, unexpectedly, that stroke mortality showed strong correlations with atmospheric pollution levels, both in winter and in summer. These correlations were strengthened, rather than dissipated, by standardisation for season and for temperature. The pattern for stroke mortality differed, in these respects, from acute myocardial infarction. The pollution correlations of hypertension deaths were similar to those from stroke, and they were jointly more powerful than correlations with deaths from bronchitis.

Deaths from cerebral thrombosis and cerebral haemorrhage in England and Wales have exhibited (a) a regular seasonal variation, being more frequent in the winter, and (b) a steep and steady downward trend, over the last 10 to 20 years. These features have been recorded in several different countries. ${ }^{1-6}$ Several investigators have demonstrated that the decline in deaths reflects a decline in incidence rather than a reduction of case fatality, and that the changes are real, and not the artefact of an altered classification of deaths. ${ }^{5-8}$ The decline is possibly a phenomenon of the last three decades. Some earlier analyses suggested that the mortality had been rising in the period before 1950, although this was certainly not true everywhere. ${ }^{9-13}$ The high fatality rates of cerebral haemorrhage in particular, and short survival times in fatal strokes, ${ }^{74}$ suggest that the seasonal pattern of mortality also reflects a seasonal variation in incidence, rather than of case fatality.

Postulated causes of the downward trend have included an altered lifestyle and a changing dietary pattern, ${ }^{15}$ especially a reduced dietary intake of salt ${ }^{16}$; also the improved detection and treatment of hypertension, salt loss from increasing uses of diuretics for reasons other than hypertension, and a variety of other factors. ${ }^{17}{ }^{18}$ However, none of the individual factors which have been examined in detail has so far provided a full explanation of the downward trend, and none has jointly explained the trend and the seasonal variation.

The question arises whether these incomplete 'explanations', and the secular and seasonal changes, might reflect a common general mechanism. In particular, salt-balance changes in the population might be effected through a combination of dietary changes, increased usage of diuretics, and variations in ambient temperature. The general downward trend might be explained by the first two, while changed fluid dynamics in warm weather, with salt loss in sweat and urine, might account for the seasonal variations.

For these reasons it seemed desirable to investigate the meteorological associations of cerebrovascular disease mortality in more detail. By examining seasonal variations over a number of years it should be possible to show whether mortality variations are specifically related to temperature, and whether there is greater variation between warm and cool summers than between cold and very cold winters. This would clarify the fluid balance element of the model outlined above. A suitably extended data base should also permit comparisons between 
cerebrovascular disease and other causes of mortality, and between temperature and other meteorological variables.

\section{Material and method}

Mortality data for cerebrovascular disease were extracted from the reports of the Office of Population Censuses and Surveys (OPCS) ${ }^{19}{ }^{20}$ for each month over a period of nine years from 1968 to 1976 . The data were adjusted to correspond with a constant notional 30-day month, and were listed for each sex separately, and for both sexes together.

Meteorological data from the same sources ${ }^{212}$ were assembled in parallel. These included monthly statements of (a) mean daily temperature, (b) total hours of sunshine, (c) total rainfall, (d) daily maxima within each month of particulate atmospheric pollution in $\mu \mathrm{g} / \mathrm{m}^{3}$, and (e) mean daily values, also in $\mu \mathrm{g} / \mathrm{m}^{3}$. These data were recorded at a single station (Kew Observatory) in London. This limits the value which can be placed upon the information, but so long as we confine our attention to monthly values, the results probably correlate closely with conditions prevailing in England and Wales as a whole. Statistical analyses were based mainly upon the calculation of correlation coefficients between the mortality and the meteorological data, together with a range of standardisation procedures.

\section{Results}

Table 1 lists correlation coefficients between the main groups of deaths and meteorological variables. There were no substantial differences between the sexes in any of the examinations, so both sexes are examined together. The correlations with hours of sunshine followed the pattern for temperature; they disappeared when standardised with temperature, and will not be considered further. Rainfall associations were weak and irregular; they too are discarded.
Temperature showed strong negative correlations with all the disease groups, and in every case this was most marked between temperature and mortality in the same month. Only acute myocardial infarction, among the specific causes, showed a stronger correlation than 'all causes'. The pollution correlations were generally weaker than the temperature correlations. Hypertension, cerebral haemorrhage, cerebral thrombosis, and bronchitis displayed stronger correlations with pollution levels than did 'all causes'. These effects were more noticeable after a two-month lag-interval, than for 'same month' correlations.

Table 2 (left-hand panel) explores the salt loss hypothesis. It examines patterns of correlation in winter and summer separately. It provides no evidence of a seasonal localisation of the effects of temperature variation, either within the cerebrovascular or within the other disease groups.

Table 2 (right-hand panel) displays a similar analysis with respect to mean daily pollution. These correlations are for 'same month' associations. Seasonal standardisation here resulted in the disappearance of the positive correlations (see Table 1) between pollution levels and heart disease, but not between pollution levels on the one hand, and hypertension, cerebral haemorrhage and cerebral thrombosis on the other. For these diseases, and less strongly for bronchitis, the pollution correlations persist throughout the winters and the summers. The associations resist full 'within month' standardisation, a procedure which largely dissipated the temperature correlations of these same diseases.

Table 3 (first column) displays pollution correlations following standardisation of mortalities according to temperature. The pollution correlations of hypertension, cerebral haemorrhage, and cerebral thrombosis, persist both here and in the second column, where residual between-named-month variations are also eliminated, to produce correlations based upon mortalities adjusted both for

Table 1 Correlations between disease groups and meteorological data

\begin{tabular}{|c|c|c|c|c|}
\hline \multirow[b]{2}{*}{$I C D$ causes of death } & \multicolumn{4}{|c|}{ Meteorological variables (monthly means) } \\
\hline & $T^{\circ} \mathrm{C}$ & Sun & $\begin{array}{l}P \text {-mean } \\
\text { lag }=0\end{array}$ & $\begin{array}{l}P \text {-mean } \\
l a g=2\end{array}$ \\
\hline All causes & $-0 \cdot 82$ & -0.65 & 0.48 & 0.53 \\
\hline 400 Hypertension & -0.68 & -0.57 & 0.62 & 0.70 \\
\hline 410 Acute myocardial infarction & $-0 \cdot 89$ & -0.68 & 0.42 & 0.44 \\
\hline 412 Chronic IHD & -0.77 & -0.53 & 0.26 & 0.36 \\
\hline 431 Cerebral haemorrhage & -0.62 & -0.52 & 0.63 & 0.72 \\
\hline 433 Cerebral thrombosis & -0.64 & -0.52 & 0.61 & 0.75 \\
\hline 470 Influenza & $-0 \cdot 38$ & -0.36 & $0 \cdot 31$ & 0.26 \\
\hline 480 Viral pneumonia & -0.51 & -0.42 & 0.39 & 0.52 \\
\hline 490 Bronchitis & -0.76 & -0.64 & 0.58 & 0.62 \\
\hline
\end{tabular}

'P-mean' is the mean of all the daily values of particulate pollution in $\mu \mathrm{g} / \mathrm{m}^{2}$. In the last column pollution levels are correlated with mortalities occurring two months later. Throughout the Table the total number of paired variables is 108: (12 months $\times 9$ years). 
Table 2 Winter and summer correlations of deaths from selected diseases

\begin{tabular}{|c|c|c|c|c|c|c|}
\hline \multirow[b]{2}{*}{ Causes of death } & \multicolumn{3}{|c|}{$M E A N D A I L Y T^{\circ} C$} & \multicolumn{3}{|c|}{ MEAN DAILY POLLUTION } \\
\hline & $\begin{array}{l}\text { Winter } \\
\text { months }\end{array}$ & $\begin{array}{l}\text { Summer } \\
\text { months }\end{array}$ & $\begin{array}{l}\text { Within } \\
\text { months }\end{array}$ & $\begin{array}{l}\text { Winter } \\
\text { months }\end{array}$ & $\begin{array}{l}\text { Summer } \\
\text { months }\end{array}$ & $\begin{array}{l}\text { Within } \\
\text { months }\end{array}$ \\
\hline $\begin{array}{l}\text { Acute myocardial infarction } \\
\text { Chronic IHD } \\
\text { Hypertension } \\
\text { Cerebral haemorrhage } \\
\text { Cerebral thrombosis } \\
\text { Bronchitis }\end{array}$ & $\begin{array}{l}-0.60 \\
-0.60 \\
-0.46 \\
-0.41 \\
-0.45 \\
-0.58\end{array}$ & $\begin{array}{l}-0.75 \\
-0.55 \\
-0.51 \\
-0.47 \\
-0.48 \\
-0.81\end{array}$ & $\begin{array}{l}-0.39 \\
-0.17 \\
-0.18 \\
-0.21 \\
-0.15 \\
-0.27\end{array}$ & $\begin{array}{r}-0.08 \\
-0.19 \\
0.43 \\
0.51 \\
0.45 \\
0.34\end{array}$ & $\begin{array}{r}-0.22 \\
-0 \cdot 33 \\
0 \cdot 36 \\
0 \cdot 44 \\
0 \cdot 39 \\
0 \cdot 17\end{array}$ & $\begin{array}{r}-0.29 \\
-0.34 \\
0.54 \\
0.60 \\
0.62 \\
0.46\end{array}$ \\
\hline
\end{tabular}

'Winter' correlations are for data October-March: 54 paired readings.

'Summer' correlations are for data April-September: 54 paired readings.

'Within month' correlations are based on all months, deviations of observed from mean values being calculated within named months, before aggregation: 108 paired readings.

Table 3 Pollution correlations standardised by temperature

\begin{tabular}{lcc}
\hline Cause of death & Overall & Within month \\
\hline All causes & -0.01 & -0.02 \\
Acute myocardial infarction & -0.20 & -0.44 \\
Chronic IHD & -0.30 & -0.45 \\
Hypertension & 0.29 & 0.49 \\
Cerebral haemorrhage & 0.33 & 0.57 \\
Cerebral thrombosis & 0.30 & 0.57 \\
Bronchitis & 0.19 & 0.31 \\
\hline
\end{tabular}

'Within month' standardisation as for Table 2.

temperature and for season. The pattern is strengthened and confirmed for these diseases; any effects of pollution upon heart disease disappear, or may even be inverted.

The Figure demonstrates the combined mortalities from cerebral haemorrhage and cerebral thrombosis, grouped into two-month periods, over the nine-year period; this graph is set against pollution data, also grouped into two-month periods, offset by one interval of two months.

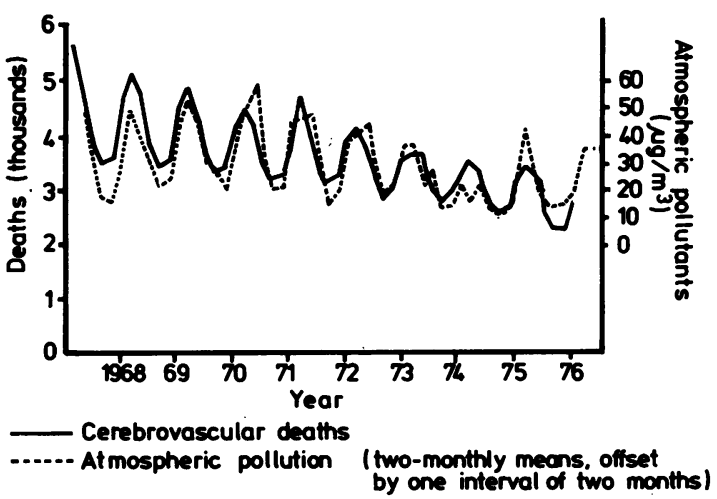

Figure Deaths from cerebral haemorrhage and cerebral thromboses (England and Wales) and mean daily values of solid atmospheric pollutants

\section{Discussion}

Firstly, the data provide no support for the hypothesis that variations of temperature influence mortality from stroke or from hypertension to different degrees in the summer and in the winter. The same conclusion applies to deaths from myocardial disease and bronchitis. It would be difficult on the basis of these data to postulate mechanisms which depended upon either the temperature extremes of winter, or the temperature extremes of summer, alone.

A second conclusion is that mortalities from cerebral haemorrhage and cerebral thrombosis, and to a lesser extent from hypertension and bronchitis, are more closely related to measures of atmospheric pollution than they are to temperature. This is particularly evident when the mortalities are related to pollution levels recorded two months previously. Standardisation for temperature, and for overall seasonal variation, confirm and accentuate these relationships. Mortality from stroke is more closely related to atmospheric pollution, both in terms of trend and of seasonal cycle, than is mortality from chronic bronchitis.

No causal inferences are drawn and the phenomenon is presented purely in a descriptive sense. However, this is not the first time that correlations between atmospheric pollution levels and cerebrovascular mortalities have been reported. The great London fog of 1952 was accompanied by an immediate increase in deaths from causes other than respiratory disease; deaths from heart disease, stroke, and hypertension were among the most prominent. ${ }^{22}$ The pollution levels occurring then were, of course, much greater than those prevalent during the nine years of the present study. The findings are also consistent with the known social and geographical distributions of mortality from stroke. ${ }^{13}$ Additional investigations are justified. 
Reprints from Professor E. G. Knox, Health Services Research Centre, Department of Social Medicine, The Medical School, Edgbaston, Birmingham BI5 2TJ.

\section{References}

${ }^{1}$ Acheson RM. Mortality from cerebrovascular disease in the United States. In: Cerebrovascular Disease Epidemiology. Public Health Monograph No. 76. Washington: US Department of Health, Education and Welfare, 1966: 23-40.

${ }^{2}$ Borhani NO. Changes and geographic distribution of mortality from cerebrovascular disease. Am J Public Health 1965; 55: 673-81.

${ }^{3}$ Habermans S, Capildeo R, Rose FC. The changing mortality of cerebrovascular disease. $Q J$ Med $1978 ; 47$ : 71-88.

${ }^{4}$ Millar GD, Kuller LH. Trends in mortality from stroke in Baltimore, Maryland. 1940-1941 through 1968-1969. Am J Epidemiol 1973; 98: 233-42.

${ }^{5}$ Prineas RJ. Cerebrovascular disease occurrence in Australia. Med J Aust 1971; 2: 509-15.

- Aubenque M, Damiana $\mathrm{P}$, Massé $\mathrm{H}$. Variations saisonnieres et series chronologiques des causes de deces en France de 1900 A 1972. Cah Sociol Demogr Med 1979; 19: 17-22.

${ }^{7}$ Eisenberg H, Morrison JT, Foote FM. Cerebrovascular accidents, incidence and survival rates in a defined population, Middlesex County, Connecticut. JAMA 1964; 189: 883-8.

${ }^{8}$ Garraway WM, Whisnant JP, Furlan AJ, Phillips LH, Kurland LT, O'Fallon WM. The declining incidence of stroke. N Engl J Med 1979; 300: 449-52.

${ }^{9}$ Acheson RM. Mortality from cerebrovascular accidents and hypertension in the Republic of Ireland. Br J Prev Soc Med 1960; 14: 139-47.
${ }^{10}$ Wylie CM. Cerebrovascular accident deaths in the United States and in England and Wales. J Chronic Dis 1962; 15: 89-90.

${ }^{11}$ Yates PO. A change in the pattern of cerebrovascular disease. Lancet 1964; i 65-9.

${ }^{12}$ Acheson RM, Williams DRR. Epidemiology of cerebrovascular disease: some unanswered questions. In: Clinical Neuroepidemiology. Rose FC, ed. London: Pitman Medical, 1980.

${ }^{13}$ Acheson RM, Sanderson C. Strokes: social class and geography. Population Trends 1978; 12: 13-7.

${ }^{14}$ Heyman A. Natural history and clinical background of cerebrovascular disease. In: Cerebrovascular Disease Epidemiology. Public Health Monograph No. 76. Washington: US Department of Health, Education and Welfare, 1966.

${ }^{15}$ Walker JW. Changing United States life-style and declining vascular mortality: cause or coincidence. $N$ Engl J Med 1977; 297: 163-5.

${ }^{16}$ Joossens JV, Kesteloot H, Amery A. Salt intake and mortality from stroke. N Engl J Med 1979; 300: 1396.

${ }^{17}$ Abu-Zeid HAH, Choi NW, Nelson NA. Epidemiologic features of cerebrovascular disease in Manitoba: incidence by age, sex and residence, with etiologic implications. Can Med Assoc J 1975; 113: 379-84.

${ }^{18}$ Freis ED. Salt, volume and the prevention of hypertension. Circulation 1976; 53: 589-95.

${ }^{10}$ Office of Population Censuses and Surveys. Mortality Statistics: Series DH1. 1974-76. (Table 12). London: HMSO,

${ }^{20}$ Registrar General. Statistical Review of England and Wales. Part 1b (Medical). 1968-1973. (Table 22) London: HMSO,

${ }^{21}$ Office of Population Censuses and Surveys. Statistics of Infectious disease: Series NB2. 1974-1976. (Table 21). London: HMSO,

${ }^{22}$ Registrar General. Statistical Review of England and Wales. Part la (Medical). 1968-1973. (Table 34). London: HMSO,

${ }^{22}$ Ministry of Health. Reports on Public Health and Medical Subjects. No. 95. Mortality and Morbidity during the London Fog of December 1952. London: HMSO, 1954. 